Research Paper

\title{
LTBP2 is a prognostic marker in head and neck squamous cell carcinoma
}

\author{
Liang Han ${ }^{1}$, Ming Ming Tang ${ }^{1}$, Xinjiang $\mathrm{Xu}^{1}{ }^{1}$, Bin Jiang ${ }^{1}$, Jianfei Huang ${ }^{2}$, Xingmei \\ Feng $^{3}$, Jianfeng Qiang ${ }^{4}$ \\ ${ }^{1}$ Department of Head and Neck Surgery, Affiliated Tumor Hospital of Nantong University, Nantong Tumor Hospital, Nantong, \\ Jiangsu, China \\ ${ }^{2}$ Department of Clinical Pathology, Affiliated Hospital of Nantong University, Nantong, Jiangsu, China \\ ${ }^{3}$ Department of Stomatology, Affiliated Hospital of Nantong University, Nantong, Jiangsu, China \\ ${ }^{4}$ Department of Graduate, Medical School of Nantong University, Nantong, Jiangsu, China \\ Correspondence to: Xingmei Feng, email: fxm1769@tom.com \\ Jianfeng Qiang, email: qjf@ntu.edu.cn
}

Keywords: head and neck squamous cell carcinoma, $q P C R$, immunohistochemistry, LTBP2, prognosis

Received: January 09, $2016 \quad$ Accepted: April 02, $2016 \quad$ Published: April 20, 2016

\section{ABSTRACT}

Latent transforming growth factor (TGF)-beta binding protein 2 (LTBP2) belongs to the fibrillin/LTBP extracellular matrix glycoprotein superfamily. It plays vital roles in tumorigenesis through regulating TGF $\beta$ activity, elastogenesis and maintenance of the extracellular matrix (ECM) structure. In this study, we determined the expression levels of LTBP 2 mRNA and protein in head and neck squamous cell carcinoma (HNSCC) tissues and adjacent normal tissues by quantitative reverse transcription PCR (qRT-PCR) and tissue microarray immunohistochemistry analysis (TMA-IHC) respectively. LTBP2 protein levels in cancer tissues were correlated with HNSCC patients' clinical characteristics and overall survival. Both LTBP2 mRNA and protein levels were significantly higher in HNSCC tissues than in adjacent normal tissues. High LTBP2 protein level was associated with lymph node metastasis and higher pTNM stages. High LTBP2 protein level is an independent prognostic marker in HNSCC. Our data suggest that LTBP2 acts as an oncogene in HNSCC development and progression. Detection of LTBP2 expression could be a useful prognosis marker and targeting LTBP2 may represent a novel strategy for cancer treatment through regulating activities of TGF $\beta$.

\section{INTRODUCTION}

Head and neck squamous cell carcinoma (HNSCC) refers to cancers arising from a variety sites within the head and neck region, including following five basic areas: the oral cavity, the pharynx, the larynx, the nasal cavity including paranasal sinuses, and the salivary glands. Overall, it accounts for approximately 600,000 new cases and 300,000 death each year worldwide [1-2]. The common risk factors include alcohol and tobacco consumption, human papillomavirus (HPV) and EpsteinBarr virus infection [3]. Males are more likely to be affected than females. The variation of disease prevalence in different regions of the world reflexes the variation of these risk factors. For example, nasopharyngeal cancer is more common in southern region of China because of EBV infection [4], while mouth and tongue cancers are more common in the subcontinent of India because of tobacco chewing [5-6]. HNSCC is a heterogeneous disease with different prognosis by disease location, with worst survival for hypopharynx and best survival for larynx. Over $50 \%$ of HNSCC cases are diagnosed as regional advanced or metastatic diseases, prognosis is better in female patients than in male patients [7-8]. Despite our improved understanding of epidemiology of HNSCC, the prognosis and overall survival of advanced HNSCC cases remain poor.

The latent transforming growth factor binding proteins (LTBPs) belong to the fibrillin superfamily of extracellular matrix (ECM) proteins characterized by a repeated domain structure including both calcium binding (cb) EGF-like domain repeats and 8-Cys TGF $\beta$ 
binding domain (TB domain) repeats [9]. They were originally isolated from the large latent TGF $\beta$ complex that were covalently linked to the TGF $\beta$ propeptide (latency associated peptide or LAP) via disulfide bonds, but are also associated with fibrillin microfibrils in the extracellular matrix (ECM) [9-10] In humans, there are four LTBP isoforms (LTBP1-4) and expressed in a wide variety of tissue types [11]. They are not only key regulators of biological activities of TGF $\beta$ family growth factors, but also important for the structural integrity of the ECM. Because both TGF $\beta$ family growth factors and ECM play important roles in tumorigenesis, LTBPs have also been implicated in malignant transformation.

Unlike other LTBPs, LTBP2 does not form covalent complexes with latent TGF $\beta$. It has been hypothesized that LTBP2 indirectly regulates the activation of TGF $\beta$ by competing with LTBP1 for the same binding site to fibrillin-1 in microfibrils. In addition, LTBP2 contains an RGD integrin recognition site, thus plays an important role in cell adhesion [12]. Both tumor suppressing and tumor promoting roles have been assigned to LTBP2: it is downregulated in nasopharyngeal carcinoma (NPC) and esophageal squamous cell carcinoma (ESCC) [13-14], while it is upregulated in cervical, liver and ovarian cancers [15-17], and LTBP2 amplification has been reported in HNSCC [18].

In the current study, we determined both mRNA and protein expression of LTBP2 in HNSCC tissue samples by quantitative reverse transcription PCR (qRT-PCR) and tissue microarray immunohistochemistry analysis (TMA-IHC) respectively, and correlated to patients' clinical characteristics.

\section{RESULTS}

\section{LTBP2 mRNA level was significantly higher in HNSCC tissues than in adjacent normal tissues}

LTBP2 mRNA level was determined in 56 fresh frozen tissue samples, including 28 cancerous tissue samples and 28 matched adjacent normal tissues. Relative LTBP2 mRNA expression level was normalized to the expression of housekeeping gene GAPDH. LTBP2 mRNA expression level was significantly higher in cancerous tissues (0.2430.02049) than in adjacent normal tissues (0.13110.01190) $(P<0.001)$ (Figure 1).

\section{LTBP2 protein level was significantly higher in HNSCC tissues than in adjacent normal tissues}

We determined LTBP2 protein expression in 459 archived HNSCC tissue blocks, including 119 tongue squamous cell carcinoma (TSCC) tissues and 51 matched adjacent normal tissues, 87 buccal squamous cell carcinoma (BSCC) tissues and 38 matched adjacent normal tissues, 114 laryngeal squamous cell carcinoma (LSCC) tissues and 50 matched adjacent normal tissues.
High LTBP2 expression was detected in $52.1 \%$ of TSCC tissues, significantly higher than $19.6 \%$ detected in adjacent normal tissues (Pearson $\chi^{2}=15.438, P<0.001$ ); high LTBP2 expression was detected in $58.6 \%$ of BSCC tissues, significantly higher than $26.3 \%$ detected in adjacent normal tissues (Pearson $\chi^{2}=11.047, P=0.001$ ); high LTBP2 expression was detected in $50.9 \%$ of LSCC tissues, significantly higher than $20.0 \%$ detected in adjacent normal tissues (Pearson $\chi^{2}=13.653, P<0.001$ ) (Table 1) (Figure 2).

\section{Association of LTBP2 expression with HNSCC clinical characteristics}

Next, we correlated LTBP2 protein expression with HNSCC patients' clinical characteristics, including tobacco and alcohol consumption. High LTBP2 protein expression was significantly associated with the presence of lymph node metastasis $(P=0.004)$ and higher stage (pTNM stage III-IV, $P=0.002$ ) (Table 2).

\section{High LTBP2 expression predicts poor overall survival in HNSCC patients}

Finally, we analyzed prognostic factors in HNSCC patients using both univariate and multivariate analysis. In univariate analysis, high LTBP2 expression (HR, 4.602, 95\% CI: 2.686-7.883; $P<0.001$ ), older age at diagnosis (HR, 1.657, 95\% CI: 1.044-2.630; $P=0.032$ ), T stage (HR, 2.047, 95\% CI: 1.227-3.414; $P=0.006)$, histopathological grade (HR, 1.583, 95\% CI: 1.129-2.218; $P=0.008$ ), lymph node metastasis (HR, 5.399, 95\% CI: $3.508-8.309 ; P<0.001)$, and pTNM stage (HR, 4.842, 95\% CI: $3.097-7.571 ; P<0.001)$ were all significantly associated with overall survival. All these significant factors were then included in the multivariate analysis. In multivariate analysis, high LTBP2 expression (HR, 3.904, 95\% CI: 2.253-6.766; $P<0.001)$ and presence of lymph node metastasis (HR, 2.701, 95\% CI: 1.243-5.867; $P=0.012$ ) remain significantly associated with poor overall survival (Table 3 ). Similar results were shown by the Kaplan-Meier survival curve (log rank, $P<0.001$, Figure 3).

\section{DISCUSSION}

In the current study, we determined mRNA and protein expression levels of LTBP2 in both HNSCC and adjacent normal tissues. LTBP2 mRNA level was significantly higher in HNSCC tissues than in adjacent normal tissues. Similarly, LTBP2 protein level was significantly higher in HNSCC tissues than in adjacent normal tissues. High LTBP2 protein level was associated with lymph node metastasis and higher pTNM stages. Finally, high LTBP2 protein expression is an independent prognostic marker for poor overall survival in HNSCC patients. 
Table 1: LTBP2 protein expression in TSCC, BSCC and LSCC tissues and their adjacent normal tissues

\begin{tabular}{l} 
Groups \\
\multirow{2}{*}{ No. }
\end{tabular}

$* p<0.05$.

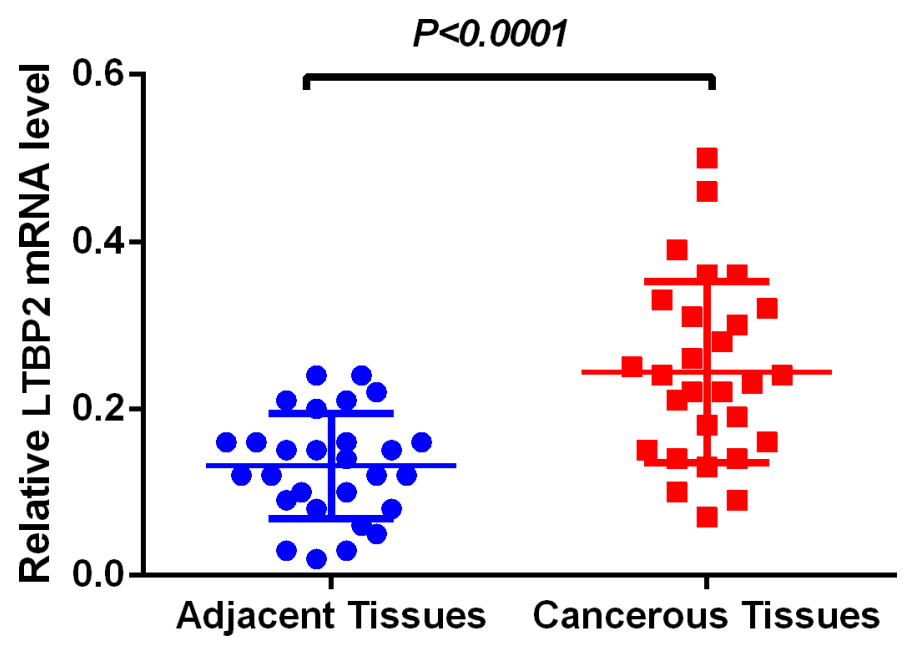

Figure 1: LTBP2 mRNA level was significantly higher in HNSCC tissues than in adjacent normal tissues. LTBP2 mRNA was determined by qRT-PCR and relative quantification analysis by normalizing to GAPDH mRNA.

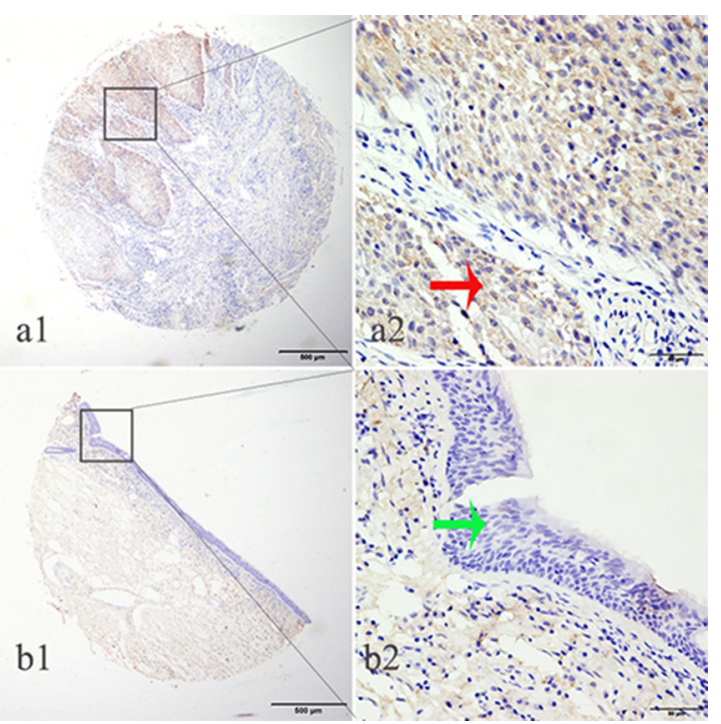

Figure 2: LTBP2 protein was detected in HNSCC tissues but not in adjacent normal tissues. LTBP2 protein was determined by TMA-IHC, a1-a2) HNSCC tissue, positive for LTBP2 protein expression; b1-b2) adjacent normal tissue, negative for LTBP2 protein expression. $\mathrm{a} 1$ and $\mathrm{b} 1$ are $\times 40$ magnification $(\mathrm{bar}=500 \mu \mathrm{m})$, a2 and $\mathrm{b} 2$ are $\times 400$ magnification $(\mathrm{bar}=50 \mu \mathrm{m})$. Red arrows indicate positive LTBP2 protein expression on cancerous epithelial cytoplasm, and green arrows indicate negative LTBP2 protein expression on adjacent normal tissue. 
Table 2: Correlation of LTBP2 protein expression with clinical characteristics of HNSCC patients

\begin{tabular}{|c|c|c|c|c|c|}
\hline \multirow{2}{*}{ Groups } & \multirow{2}{*}{ No. } & \multicolumn{2}{|c|}{ LTBP2 expression } & \multirow{2}{*}{$\chi^{2}$} & \multirow{2}{*}{$p$ value } \\
\hline & & High expression $(\%)$ & No or Low expression (\%) & & \\
\hline Total & 320 & 171 & 149 & - & - \\
\hline \multicolumn{6}{|l|}{ Age (years) } \\
\hline$\leq 60 \mathrm{y}$ & 123 & $63(51.2)$ & $60(48.8)$ & \multirow{2}{*}{0.395} & \multirow{2}{*}{0.530} \\
\hline$>60 y$ & 197 & $108(54.8)$ & $89(45.2)$ & & \\
\hline \multicolumn{6}{|l|}{ Gender } \\
\hline Female & 117 & $64(54.7)$ & $53(45.3)$ & \multirow{2}{*}{0.118} & \multirow{2}{*}{0.731} \\
\hline Male & 203 & $107(52.7)$ & $96(47.3)$ & & \\
\hline \multicolumn{6}{|l|}{ Tobacco consumption } \\
\hline Yes & 65 & $32(49.2)$ & $33(50.8)$ & \multirow{2}{*}{0.965} & \multirow{2}{*}{0.326} \\
\hline No & 192 & $108(56.3)$ & $84(43.8)$ & & \\
\hline Unknown & 63 & & & & \\
\hline \multicolumn{6}{|l|}{ Alcohol consumption } \\
\hline Yes & 129 & $67(51.9)$ & $62(48.1)$ & \multirow{2}{*}{0.202} & \multirow{2}{*}{0.653} \\
\hline No & 139 & $76(54.7)$ & $63(45.3)$ & & \\
\hline Unknown & 52 & & & & \\
\hline \multicolumn{6}{|l|}{ Tumor location } \\
\hline Oral & 206 & $113(54.9)$ & $93(45.1)$ & \multirow{2}{*}{0.467} & \multirow{2}{*}{0.495} \\
\hline Larynx & 114 & $58(50.9)$ & $56(49.1)$ & & \\
\hline \multicolumn{6}{|l|}{ Tumor classification } \\
\hline TSCC & 119 & $62(52.1)$ & $57(47.9)$ & \multirow{3}{*}{1.325} & \multirow{3}{*}{0.516} \\
\hline BSCC & 87 & $51(58.6)$ & $36(41.4)$ & & \\
\hline LSCC & 114 & $58(50.9)$ & $56(49.1)$ & & \\
\hline \multicolumn{6}{|c|}{ Histopathological grade } \\
\hline High & 168 & $87(51.8)$ & $81(48.2)$ & \multirow{3}{*}{1.203} & \multirow{3}{*}{0.548} \\
\hline Moderate & 126 & $71(56.3)$ & $55(43.7)$ & & \\
\hline Low & 14 & $9(64.3)$ & $5(35.7)$ & & \\
\hline Unknown & 12 & & & & \\
\hline T stage & & & & & \\
\hline $\mathrm{T} 1+\mathrm{T} 2$ & 228 & $124(54.4)$ & $104(45.6)$ & 0652 & 0410 \\
\hline $\mathrm{T} 3+\mathrm{T} 4$ & 34 & $21(61.8)$ & $13(38.2)$ & 0.052 & 0.419 \\
\hline Unknown & 58 & & & & \\
\hline Lymph node metastas & & & & & \\
\hline Yes & 74 & $52(70.3)$ & $22(29.7)$ & 8203 & $0 \Omega 04 *$ \\
\hline No & 210 & $105(50.0)$ & $105(50.0)$ & 0.293 & 0.004 \\
\hline Unknown & 36 & & & & \\
\hline pTNM stage & & & & & \\
\hline Stage I + II & 170 & $82(48.2)$ & $88(51.8)$ & 0808 & $0002 *$ \\
\hline Stage III + IV & 92 & $63(68.5)$ & $29(31.5)$ & 9.090 & 0.002 \\
\hline Unknown & 58 & & & & \\
\hline
\end{tabular}
$* p<0.05$. 
LTBPs are key regulators of TGF $\beta$ activities, including cell growth, cell invasion, differentiation and morphogenesis [11]. TGF $\beta$ is secreted as a large latent complex (LLC) comprised of mature dimeric TGF $\beta$, TGF $\beta$ propeptide (also known as latency-associated propeptide, LAP) and LTBP. LTBPs participate and regulate every step of TGF $\beta$ 's biology: from folding, assembling, secretion, localization to activation. In the endoplasmic reticulum (ER), LTBP functions as the chaperone assisting the proper folding of TGF $\beta$ and LAP, assembling of TGF $\beta$ and LAP into small latent complex (SLC) then LLC, and efficient secretion of LLC [10]. Secreted LLC is stored in the ECM through interactions between LTBP and multiple extracellular proteins, and TGF $\beta$ activation is initiated through recognition of LTBP by integrin and enzymatic degradation of LTBP [10, 23-24]. The role of LTBPs in tumorigenesis is mainly through regulating TGF $\beta$ activities [25-26]. However, LTBPs also interact with other potent growth factors and important structural proteins of the ECM, playing vital roles in organ formation and tissue homeostasis [11]. It has been proposed that LTBPs can influence the structure of tumor stroma independent of TGF $\beta$ 's activities [27].

During tumor initiation, TGF $\beta$ is tumor suppressive through its growth inhibition activity; but during tumor progression, TGF $\beta$ can promote invasion, metastasis, angiogenesis and immunosuppression [24]. Thus it is not surprising that both tumor promoting and tumor suppressing functions have been proposed for LTBP2. LTBP2 protein was upregulated in pancreatic cancer tissue samples [28] and plasma samples from hepatocellular carcinoma (HCC) patients [16]. LTBP2 was upregulated in cervical cancer cells and associated with clinical stage, tumor size, depth of stromal invasion and lymph node metastasis [16]. High LTBP2 protein expression predicts poor survival in serous ovarian carcinoma [17]. Mechanistic studies demonstrated that LTBP2 knockdown inhibited tumor proliferation and migration, and MAPK, PI3K-AKT, RTK and p53 signaling pathways were involved in cervical carcinogenesis [15]. In colon cancer, LTBP2 was upregulated in tumor stromal cells, but not in cancer epithelial cells [29]. On the other hand, LTBP2 was epigenetically silenced in several cancer types: LTBP2 is methylated in chronic lymphocytic leukemia (CLL) [30]; in melanoma, LTBP2 is epigenetically silenced to promote TGF $\beta$ mediated cell invasion [31]; in NPC, LTBP2 is methylated to inactivate NF- $\mathrm{\kappa B}$ p65 protein mediated oncogenic signaling pathway $[13,32]$. In ESCC, both tumor suppressing and tumor promoting functions have been observed for LTBP2: it was epigenetically downregulated in tumor tissues compared to normal tissues; however, low tumor cell LTBP2 expression predicts better overall survival [14]. Our data suggest that LTBP2 acts as an oncogene in HNSCC.

Our study has several limitations. First, our study samples were limited to Chinese population and subject to sample selection bias, so our conclusions may not be extended to other populations without further validation from future larger international studies. Second, our current study only included oral cavity squamous cell carcinoma (65\%) and laryngeal squamous cell carcinoma $(35 \%)$. It is known that HNSCC is a heterogeneous disease with different prognosis by tumor location. In European populations, the relative survival for patients with hypopharyngeal squamous cell carcinoma is only $25 \%$, while the relative survival for patients with laryngeal
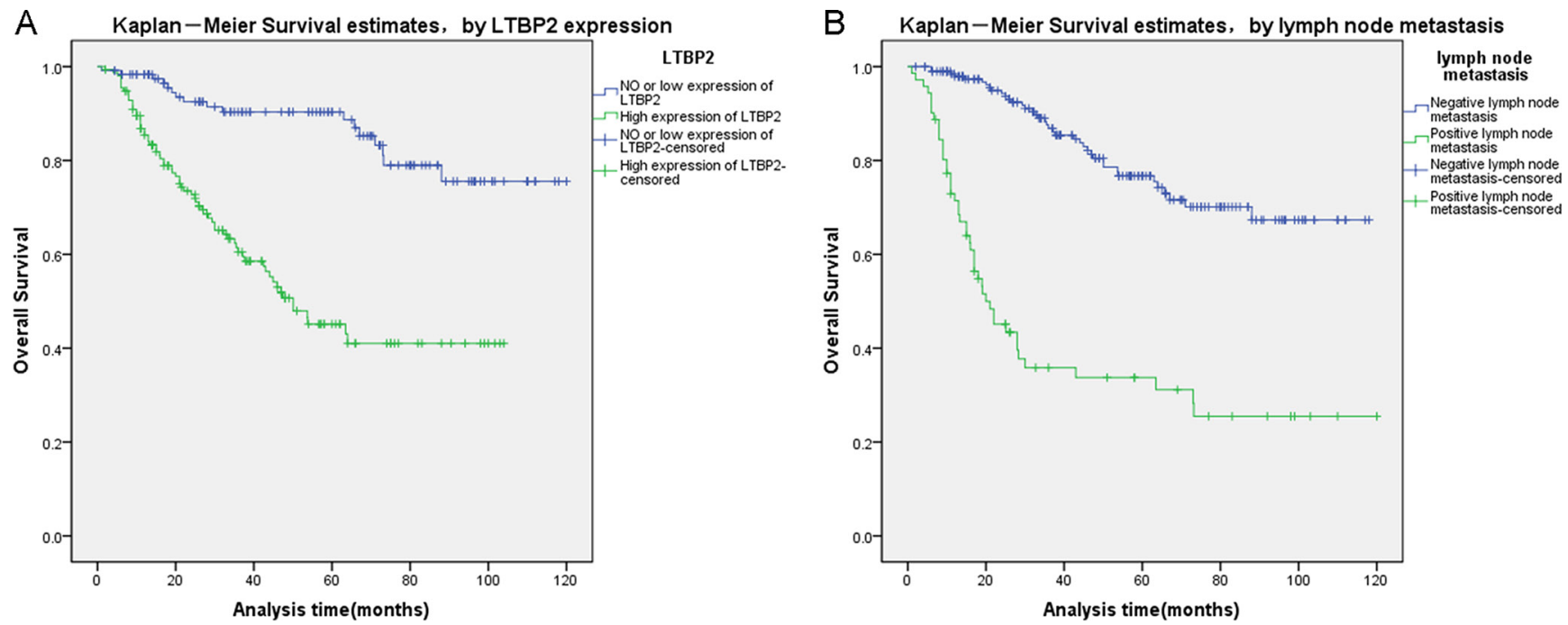

Figure 3: Survival curves of HNSCC patients by the Kaplan-Meier method and the log-rank test. (A) LTBP2+ HNSCC patients (green line, 1) had significantly worse overall survival than LTBP- patients (blue line, 0). (B) HNSCC patients with lymph node metastasis (green line, 1) had significantly worse overall survival than patients without lymph node metastasis (blue line, 0 ). 
Table 3: Univariate and multivariate analysis of prognostic factors for overall survival in HNSCC Patients

\begin{tabular}{|c|c|c|c|c|c|c|}
\hline & \multicolumn{3}{|c|}{ Univariate analysis } & \multicolumn{3}{|c|}{ Multivariate analysis } \\
\hline & HR & $p$ value & $95 \% \mathrm{CI}$ & HR & $p$ value & $95 \%$ CI \\
\hline \multicolumn{7}{|l|}{ LTBP2 expression } \\
\hline High vs Low & 4.602 & $0.001 *$ & $2.686-7.883$ & 3.904 & $0.001^{*}$ & $2.253-6.766$ \\
\hline \multicolumn{7}{|l|}{ Age (years) } \\
\hline$\leq 60 \mathrm{y} v \mathrm{vs}>60 \mathrm{y}$ & 1.657 & $0.032 *$ & $1.044-2.630$ & & & \\
\hline \multicolumn{7}{|l|}{ Gender } \\
\hline Female vs male & 1.222 & 0.391 & $0.774-1.929$ & & & \\
\hline \multicolumn{7}{|l|}{ Tobacco consumption } \\
\hline Yes vs No & 1.033 & 0.895 & $0.634-1.685$ & & & \\
\hline \multicolumn{7}{|l|}{ Alcohol consumption } \\
\hline Yes vs No & 0.987 & 0.954 & $0.631-1.544$ & & & \\
\hline \multicolumn{7}{|l|}{ Tumor location } \\
\hline Oral vs Larynx & 1.194 & 0.424 & $0.773-1.843$ & & & \\
\hline \multicolumn{7}{|l|}{ Histopathological grade } \\
\hline High vs Moderate vs Low & 1.583 & $0.008^{*}$ & $1.129-2.218$ & 1.216 & 0.296 & $0.842-1.757$ \\
\hline \multicolumn{7}{|l|}{ T stage } \\
\hline $\mathrm{T} 1+\mathrm{T} 2$ vs $\mathrm{T} 3+\mathrm{T} 4$ & 2.047 & $0.006^{*}$ & $1.227-3.414$ & 1.338 & 0.425 & $0.654-2.738$ \\
\hline \multicolumn{7}{|l|}{ Lymph node metastasis } \\
\hline Yes vs No & 5.399 & $0.001 *$ & $3.508-8.309$ & 2.701 & $0.012^{*}$ & $1.243-5.867$ \\
\hline \multicolumn{7}{|l|}{ pTNM stage } \\
\hline Stage I, II vs Stage III, IV & 4.842 & $0.001 *$ & $3.097-7.571$ & 1.991 & 0.122 & $0.832-4.767$ \\
\hline
\end{tabular}

$* p<0.05$.

squamous cell carcinoma is about $59 \%$. Thus, we do not know whether our conclusions can be extended to all HNSCC sites. Third, we only included alcohol and tobacco consumption risk factors in our analysis, but not other two known risk factors for HNSCC: HPV and EBV infection. Fourth, we did not determine whether LTBP2 overexpression was due to DNA amplification. Earlier studies have reported that LTBP2 was highly amplified in HNSCC [14]. Finally, our clinical data were not complete, for example, we did not have treatment history during follow-up. Although we excluded the missing data points for the statistical analysis, future studies are needed to confirm our results.

In conclusion, our study demonstrates the involvement of LTBP2 in HNSCC and as an independent prognostic marker for HNSCC in Chinese population. Because of the essential role LTBPs play in regulating TGF $\beta$ activity and additional function in maintaining ECM structure, the elucidation of the molecular mechanisms of LTBPs will help understanding the role of TGF $\beta$ in tumorigenesis and tumor progression, and allow the development of optimal therapeutic agents that target the activity of TGF $\beta$ in cancer.

\section{MATERIALS AND METHODS}

\section{Human tissue specimens and patient clinical information}

A total of 348 HNSCC patients were included in the study. Twenty eight HNSCC patients were consented and enrolled before surgery, and 56 fresh tissue samples were collected and frozen at the time of surgery. In addition, 320 HNSCC patients provided 459 archived formalinfixed paraffin-embedded (FFPE) tissue blocks. Clinical characteristics were obtained from patients' medical records. The study protocol was approved by the Human Research Ethics Committee of the Affiliated Hospital of Nantong University, Jiangsu, China.

\section{LTBP2 expression and statistical analysis}

LTBP2 mRNA level was determined by quantitative reverse transcription PCR [19]. Relative quantification was performed using $\Delta \Delta \mathrm{Ct}$ method by first normalizing to housekeeping gene GAPDH mRNA level, then normalizing to the reference sample. By selecting and 
averaging the expression of five low stage ( $\leq$ stage II) tumor samples. The primers used are as follows: LTBP2 forward primer (5'- TTA CAA GCA GAG ACT CAC T-3') and LTBP2 reverse primer (5'- ACA ACA GAA GAG ACC AGA T-3'), GAPDH forward primer (5'-TGC ACC ACC AAC TGC TTA GC-3') and GAPDH reverse primer (5'-GGC ATG GAC TGT GGT CAT GAG-3'). LTBP2 protein expression in tissue blocks was determined using tissue microarray immunohistochemistry (TMA IHC) [19]. Rabbit polyclonal anti-human LTBP2 antibody was used (dilution 1:800, ab121193, Abcam, USA). The LTBP2 protein level was quantified using a two-level grading system, and the staining scores were defined as follows: 0-3, low expression; 4-9, high expression. The LTBP2 IHC data were also scored using the semi-quantitative $\mathrm{H}$-score method and analyzed using the X-tile software program (The Rimm Lab at Yale University; http:// medicine.yale.edu/lab/rimm/links/) [20-22]. Statistical analysis was performed as described before [19].

\section{CONFLICTS OF INTEREST} interests.

The authors declared that they have no competing

\section{ACKNOWLEDGMENTS AND FUNDING}

This investigation was supported by grants from Science and Technique Development Fund (MS22015108) of Nantong, Jiangsu, China, and Academy level fund of Nantong Tumor Hospital, Nantong, Jiangsu, China

\section{REFERENCES}

1. Siegel RL, Miller KD, Jemal A. Cancer statistics, 2015. CA Cancer J Clin. 2015; 65:5-29.

2. Wyss A, Hashibe M, Chuang SC, Lee YC, Zhang ZF, Yu GP, Winn DM, Wei Q, Talamini R, Szeszenia-Dabrowska N, Sturgis EM, Smith E, Shangina O, et al. Cigarette, cigar, and pipe smoking and the risk of head and neck cancers: pooled analysis in the International Head and Neck Cancer Epidemiology Consortium. Am J Epidemiol. 2013; 178:679-690.

3. Sankaranarayanan R, Masuyer E, Swaminathan R, Ferlay J, Whelan S. Head and neck cancer: a global perspective on epidemiology and prognosis. Anticancer Res. 1998; 18:4779-4786.

4. Raghupathy R, Hui EP, Chan AT. Epstein-Barr virus as a paradigm in nasopharyngeal cancer: from lab to clinic. Am Soc Clin Oncol Educ Book. 2014:149-153.

5. Bray F, Ren JS, Masuyer E, Ferlay J. Global estimates of cancer prevalence for 27 sites in the adult population in 2008. Int J Cancer. 2013; 132:1133-1145.

6. Lambert R, Sauvaget C, de Camargo Cancela M, Sankaranarayanan R. Epidemiology of cancer from the oral cavity and oropharynx. Eur J Gastroenterol Hepatol. 2011; 23:633-641.

7. Gatta G, Botta L, Sanchez MJ, Anderson LA, Pierannunzio D, Licitra L. Prognoses and improvement for head and neck cancers diagnosed in Europe in early 2000s: The EUROCARE-5 population-based study. Eur J Cancer. 2015.

8. Curado MP, Hashibe M. Recent changes in the epidemiology of head and neck cancer. Curr Opin Oncol. 2009; 21:194-200.

9. Robertson IB, Horiguchi M, Zilberberg L, Dabovic B, Hadjiolova K, Rifkin DB. Latent TGF-beta-binding proteins. Matrix Biol. 2015; 47:44-53.

10. Hyytiainen M, Penttinen C, Keski-Oja J. Latent TGF- beta binding proteins: extracellular matrix association and roles in TGF-beta activation. Crit Rev Clin Lab Sci. 2004; 41:233-264.

11. Todorovic V, Rifkin DB. LTBPs, more than just an escort service. J Cell Biochem. 2012; 113:410-418.

12. Vehvilainen $P$, Hyytiainen M, Keski-Oja J. Latent transforming growth factor-beta-binding protein 2 is an adhesion protein for melanoma cells. J Biol Chem. 2003; 278:24705-24713.

13. Kan R, Shuen WH, Lung HL, Cheung AK, Dai W, Kwong DL, Ng WT, Lee AW, Yau CC, Ngan RK, Tung SY, Lung ML. NF-kappaB p65 Subunit Is Modulated by Latent Transforming Growth Factor-beta Binding Protein 2 (LTBP2) in Nasopharyngeal Carcinoma HONE1 and HK1 Cells. PLoS One. 2015; 10:e127239.

14. Chan SH, Yee Ko JM, Chan KW, Chan YP, Tao Q, Hyytiainen M, Keski-Oja J, Law S, Srivastava G, Tang J, Tsao SW, Chen H, Stanbridge EJ, et al. The ECM protein LTBP-2 is a suppressor of esophageal squamous cell carcinoma tumor formation but higher tumor expression associates with poor patient outcome. Int J Cancer. 2011; 129:565-573.

15. Ren Y, Lu H, Zhao D, Ou Y, Yu K, Gu J, Wang L, Jiang S, Chen M, Wang J, Zhang R, Xu C. LTPB2 acts as a prognostic factor and promotes progression of cervical adenocarcinoma. Am J Transl Res. 2015; 7:1095-1105.

16. da Costa AN, Plymoth A, Santos-Silva D, Ortiz-Cuaran S, Camey S, Guilloreau P, Sangrajrang S, Khuhaprema T, Mendy M, Lesi OA, Chang HK, Oh JK, Lee DH, et al. Osteopontin and latent-TGF beta binding-protein 2 as potential diagnostic markers for HBV-related hepatocellular carcinoma. Int J Cancer. 2015; 136:172-181.

17. Yoshihara K, Tajima A, Komata D, Yamamoto T, Kodama S, Fujiwara H, Suzuki M, Onishi Y, Hatae M, Sueyoshi K, Kudo Y, Inoue I, et al. Gene expression profiling of advanced-stage serous ovarian cancers distinguishes novel subclasses and implicates ZEB2 in tumor progression and prognosis. Cancer Sci. 2009; 100:1421-1428.

18. Jarvinen AK, Autio R, Kilpinen S, Saarela M, Leivo I, Grenman R, Makitie AA, Monni O. High-resolution copy number and gene expression microarray analyses of head 
and neck squamous cell carcinoma cell lines of tongue and larynx. Genes Chromosomes Cancer. 2008; 47:500-509.

19. Xu Y, Wang C, Zhang Y, Jia L, Huang J. Overexpression of MAGE-A9 Is Predictive of Poor Prognosis in Epithelial Ovarian Cancer. Sci Rep. 2015; 5:12104.

20. Detre S, Saclani Jotti G, Dowsett M. A “quickscore” method for immunohistochemical semiquantitation: validation for oestrogen receptor in breast carcinomas. J Clin Pathol. 1995; 48:876-878.

21. Huang J, Fan X, Wang X, Lu Y, Zhu H, Wang W, Zhang S, Wang Z. High ROR2 expression in tumor cells and stroma is correlated with poor prognosis in pancreatic ductal adenocarcinoma. Sci Rep. 2015; 5:12991.

22. Lu C, Wang X, Zhu H, Feng J, Ni S, Huang J. Overexpression of ROR2 and Wnt5a cooperatively correlates with unfavorable prognosis in patients with non-small cell lung cancer. Oncotarget. 2015; 6:24912-24921. doi: 10.18632/oncotarget.4701.

23. Saharinen J, Hyytiainen M, Taipale J, Keski-Oja J. Latent transforming growth factor-beta binding proteins (LTBPs) - structural extracellular matrix proteins for targeting TGF-beta action. Cytokine Growth Factor Rev. 1999; 10:99-117.

24. Taipale J, Saharinen J, Keski-Oja J. Extracellular matrixassociated transforming growth factor-beta: role in cancer cell growth and invasion. Adv Cancer Res. 1998; 75:87-134.

25. Chandramouli A, Simundza J, Pinderhughes A, Cowin P. Choreographing metastasis to the tune of LTBP. J Mammary Gland Biol Neoplasia. 2011; 16:67-80.

26. Oklu R, Hesketh R. The latent transforming growth factor beta binding protein (LTBP) family. Biochem J. 2000; 352 Pt 3:601-610.
27. Vehvilainen P, Koli K, Myllarniemi M, Lindholm P, Soini Y, Salmenkivi K, Kinnula VL, Keski-Oja J. Latent TGF-beta binding proteins (LTBPs) 1 and 3 differentially regulate transforming growth factor-beta activity in malignant mesothelioma. Hum Pathol. 2011; 42:269-278.

28. Turtoi A, Musmeci D, Wang Y, Dumont B, Somja J, Bevilacqua G, De Pauw E, Delvenne P, Castronovo V. Identification of novel accessible proteins bearing diagnostic and therapeutic potential in human pancreatic ductal adenocarcinoma. J Proteome Res. 2011; 10:4302-4313.

29. Torres S, Bartolome RA, Mendes M, Barderas R, FernandezAcenero MJ, Pelaez-Garcia A, Pena C, Lopez-Lucendo M, Villar-Vazquez R, de Herreros AG, Bonilla F, Casal JI. Proteome profiling of cancer-associated fibroblasts identifies novel proinflammatory signatures and prognostic markers for colorectal cancer. Clin Cancer Res. 2013; 19:6006-6019.

30. Tong WG, Wierda WG, Lin E, Kuang SQ, Bekele BN, Estrov Z, Wei Y, Yang H, Keating MJ, GarciaManero G. Genome-wide DNA methylation profiling of chronic lymphocytic leukemia allows identification of epigenetically repressed molecular pathways with clinical impact. Epigenetics. 2010; 5:499-508.

31. Rai K, Akdemir KC, Kwong LN, Fiziev P, Wu CJ, Keung EZ, Sharma S, Samant NS, Williams M, Axelrad JB, Shah A, Yang D, Grimm EA, et al. Dual Roles of RNF2 in Melanoma Progression. Cancer Discov. 2015; 5:1314-1327.

32. Chen H, Ko JM, Wong VC, Hyytiainen M, Keski-Oja J, Chua D, Nicholls JM, Cheung FM, Lee AW, Kwong DL, Chiu PM, Zabarovsky ER, Tsao SW, et al. LTBP-2 confers pleiotropic suppression and promotes dormancy in a growth factor permissive microenvironment in nasopharyngeal carcinoma. Cancer Lett. 2012; 325:89-98. 